\title{
Original Research \\ Genetic variants in obesity-related genes and the risk of osteoporotic fracture. The Hortega Follow-up Study
}

\author{
Ricardo Usategui-Martín ${ }^{1,2,3, *, \dagger}$, Jose Luis Pérez-Castrillón ${ }^{4,5, *, \dagger}$, Laisa Briongos-Figuero $^{4}$, \\ Jesica Abadía-Otero ${ }^{4}$, Francisco Lara-Hernandez ${ }^{6}$, Soraya García-Sorribes ${ }^{6}$, \\ Javier Martín-Vallejo ${ }^{7}$, Ana B. García-García ${ }^{6,8}$, Felipe J. Chaves ${ }^{6,8}$, \\ Juan Carlos Martín-Escudero ${ }^{4,5}$ \\ ${ }^{1}$ IOBA, University of Valladolid, 47011 Valladolid, Spain \\ ${ }^{2}$ Cooperative Health Network for Research (RETICS), Oftared, National Institute of Health Carlos III, ISCIII, 28040 Madrid, Spain \\ ${ }^{3}$ Regenerative Medicine and Cell Therapy Network Centre of Castilla y León, 47011 Valladolid, Spain \\ ${ }^{4}$ Department of Internal Medicine, Rio Hortega Universitary Hospital, 47012 Valladolid, Spain \\ ${ }^{5}$ Department of Medicine, Faculty of Medicine, University of Valladolid, 47002 Valladolid, Spain \\ ${ }^{6}$ Genomic and Genetic Diagnosis Unit, INCLIVA Biomedical Research Institute, 46010 Valencia, Spain \\ ${ }^{7}$ Department of Statistics, University of Salamanca, Salamanca Biomedical Research Institute (IBSAL), 37008 Salamanca, Spain \\ ${ }^{8}$ CIBER of Diabetes and Associated Metabolic Diseases (CIBERDEM), 28029 Madrid, Spain \\ *Correspondence: uvacastrv@gmail.com (José Luis Pérez-Castrillon); rusategui@gmail.com (Ricardo Usategui-Martín) \\ $\dagger$ These authors contributed equally. \\ Academic Editor: Alexandros Georgakilas \\ Submitted: 30 September 2021 Revised: 28 December 2021 Accepted: 28 December 2021 Published: 18 January 2022
}

\begin{abstract}
Background: Osteoporosis and obesity are major public health problems that are closely correlated, as they share various features, including a genetic predisposition. A genetic correlation between obesity and osteoporosis due to the biological common pathways of bone and fat metabolism, which implies pleiotropic genes regulating has been described. The objective of our study was to analyse whether polymorphisms in obesity-related genes modify the risk of osteoporotic bone fracture. Methods: We studied 575 subjects from the Hortega Study. The subjects were followed-up for 12-14 years. 202 subjects were overweight, 143 obese and 221 had bone fractures. The distribution of 39 genetic variants in 22 obesity-related genes were studied. Results: The results showed a relationship between polymorphisms in the FTO and NEGR1 genes and the susceptibility to osteoporotic fracture. The variant genotype of the rs 2568958 NEGR1 polymorphism and the rs6499649, rs3751812, and rs8044769 genetic variants in FTO were associated with susceptibility to bone fracture. In the best of our knowledge, this is the first time that these variants in NEGRI and FTO genes have been associated with the susceptibility to osteoporotic bone fracture, supporting the hypothesis that the NEGRI and FTO genes might be candidates for osteoporosis and bone fracture. Conclusions: In conclusion, this study associates obesity-related polymorphisms in the NEGRI and FTO genes with osteoporotic bone fracture, reinforcing the hypothesis that obesity and bone metabolism are closely correlated genetically.
\end{abstract}

Keywords: Osteoporosis; Bone fracture; Obesity; Polymorphism; FTO and NEGR1

\section{Introduction}

Osteoporosis (OMIM: 166710) is a chronic, progressive, silent, and systemic bone metabolism disease caused by reduced bone mineral density (BMD) and alterations in the tissue microarchitecture, increasing the risk of fragility fractures $[1,2]$. Osteoporosis is the most prevalent chronic bone metabolism disease worldwide. The main clinical complication of osteoporosis is bone fracture, and it is associated with worse quality of life and with higher disability, morbidity and mortality [3-5]. Bone is a dynamic tissue, with a balance between bone formation osteoblast-mediated and osteoclast-mediated bone resorption. The underlying pathological mechanism in osteoporosis is an unbalance between bone resorption and bone formation, which leads to increased bone fragility and higher risk of osteoporotic fracture [6].
The aetiology of osteoporosis is closely associated with genetic factors. Family studies have shown that 50 $80 \%$ of the osteoporotic risk is explained by genetic variants, and multiple genes/loci have been associated with BMD phenotypes and fractures $[7,8]$. In addition, the risk of fragility bone fracture is higher in patients with a family history of osteoporosis [9-11]. Environmental factors are also important in the aetiology of osteoporosis, and the most accepted hypothesis is the combined action of environmental and genetic determinants [2-4].

Obesity, another major public health problem, is closely related to osteoporosis, with which it shares several features, including a genetic predisposition and a common progenitor cell [12-14]. Adipocytes and osteoblasts arise from bone marrow stem cells (BMSC) and both transdifferentiate into each other [15]. Age is an independent risk fac- 
tor for osteoporosis: it has been reported that, with aging, the differentiation of BMSC shifts to favour adipocytes, decreasing osteoblast functions and leading to the risk osteoporosis and fracture [16,17]. In addition, adipocytes have an important role in bone metabolism through the secretion of factors such as the oestrogen synthesis enzyme, aromatase, leptin and proinflammatory cytokines [15,18]. There is a common central regulation of bone metabolism and metabolic fate through the hypothalamus and sympathetic nervous system $[13,19,20]$. A possible protective effect of fat on the skeleton with respect to the risk of bone loss and fragility fracture has been described [13,21,22]. Genetic factors play crucial role in osteoporosis and obesity, with a genetic correlation between them due to the biological common pathways of bone and fat metabolism, which implies pleiotropic genes regulating both processes [23-25]. Therefore, the principal objective of our study was to analyse if polymorphisms in obesity-related genes could modify the susceptibility of suffering osteoporotic bone fracture.

\section{Subjects and methods}

\subsection{Subjects}

The Hortega Follow-up Study is a cross-sectional prospective study of factors associated with chronic diseases. The Hortega Study began in 2001-2003 with the baseline screening and biological samples collection, and added information on the evolution of subjects in 2015 . The participants were 1504 adults from the West Valladolid Health Area (Rio Hortega University Hospital, Spain) [2630].

To analyse the influence of polymorphisms in obesityrelated genes on the susceptibility to osteoporotic bone fracture, individuals were chosen from the Hortega Study, as previously reported [30]. In summary, of the 1504 baseline individuals, 137 subjects were excluded because lack of anthropometric, demographic or clinical data. After analysis of individuals aged over 50 years old $(\mathrm{N}=702)$, we excluded 49 subjects due to lack of clinical follow-up information, 15 subjects with a history of bone fracture at baseline and 63 individuals without bone X-ray, resulting in a final study sample of 575 individuals. Cases were considered patients with bone fracture $(\mathrm{N}=221)$ and individuals without fracture were $(\mathrm{N}=354)$ classified as control group (Supplementary Fig. 1). Subjects aged $<50$ years were excluded as the risk of osteoporotic bone fracture has been reported to increase dramatically after the age of 50 years [31]. All subjects included were Caucasian.

Anthropometric, clinical and demographic characteristics such as sex, height, age, weight, body mass index (BMI), overweight and obesity status, tobacco, alcohol, menopause, corticosteroid consumption, family history of fragility bone fracture and calcaneal bone densitometry were obtained from each subject. Type 2 diabetes mellitus, hypertension, overweigh and obesity were diag- nosed based on World Health Organization (WHO) guidelines (http://www.who.int). Peripheral instantaneous X-ray imaging (PIXI) DXA system (General Electric Lunar Pixi, Boston, MA, USA) was used to determine the calcaneal bone densitometry of the right calcaneus. Bone fractures were collected after a clinical follow up of 12-14 years. The Genant classification was used to determine vertebral fractures [32] and non-vertebral fractures were collected with the review of the medical records.

The University Hospital of Valladolid Research Ethics Committee approved the experimental protocol. Our study was in line with the Declaration of Helsinki (2008) of the World Medical Association and it also complied with Spanish data protection laws (LO 15/1999) and specifications (RD 1720/2007). All individuals who participated signed consent form.

Table 1. Anthropometric, clinical and demographic characteristics of study individuals.

\begin{tabular}{lcc}
\hline \multirow{2}{*}{ Characteristics } & \multicolumn{2}{c}{ Control group Osteoporotic fracture group } \\
\cline { 2 - 3 } & $(\mathrm{n}=354)$ & $(\mathrm{n}=221)$ \\
\hline Age (years) & $61.9(16.3)$ & $61.4(17.8)$ \\
Sex (female) & $189(53.4 \%)$ & $107(48.4 \%)$ \\
Height $(\mathrm{cm})$ & $164.5(9.1)$ & $164.1(9.5)$ \\
Weight $(\mathrm{kg})$ & $71.4(13.5)$ & $71.0(12.9)$ \\
Body mass index $\left(\mathrm{kg} / \mathrm{m}^{2}\right)$ & $26.3(4.3)$ & $26.3(4.1)$ \\
Obesity & $84(25.0 \%)$ & $59(28.2 \%)$ \\
Overweight & $123(36.5 \%)$ & $79(37.8 \%)$ \\
Central obesity & $82(24.0 \%)$ & $59(27.4 \%)$ \\
High blood pressure & $143(40.4 \%)$ & $83(37.6 \%)$ \\
Type 2 diabetes mellitus & $27(7.6 \%)$ & $14(6.3 \%)$ \\
Smoker & $81(23.2 \%)$ & $58(26.5 \%)$ \\
Alcohol intake & $67(19.0 \%)$ & $54(24.4 \%)$ \\
Postmenopausal women & $165(46.6 \%)$ & $89(40.3 \%)$ \\
Corticosteroids use & $38(10.8 \%)$ & $29(13.1 \%)$ \\
Family history of bone fracture & $1(0.3 \%)$ & $10(4.5 \%) *$ \\
Bone mineral density $\left(\mathrm{g} / \mathrm{cm}^{2}\right)$ & $0.55(0.11)$ & $0.53(0.11)$ \\
Bone mineral density $(\mathrm{t}-\mathrm{score})$ & $-0.17(1.10)$ & $-0.19(1.38)$ \\
\hline$* p<0.05$ betwen contro group & and $)$ \\
\hline
\end{tabular}

*: $p<0.05$ between control group and osteoporotic fracture group. Quantitative variables are presented as mean (standard deviation) and qualitative variables are presented as $\mathrm{n}(\%)$

\subsection{DNA isolation and polymorphism genotyping}

Genomic DNA was extracted from nucleated peripheral blood cells of patients and healthy subjects by standard commercial procedures. The obtained genomic DNA was quantified and stored to a final concentration of $100 \mathrm{ng} / \mu \mathrm{L}$. We studied 39 polymorphisms in 22 obesity-related genes (Supplementary Table 1). The selection of genetic variants was made through SYSNP [33,34] and computer-based searches in Web of Science, PubMed, Embase and Scopus databases with the following terms: "bone metabolism", "obesity", "polymorphisms", "genetic variants", "SNPs", 
Table 2. Genetic variants in obesity-related genes significantly associated with body mass index.

\begin{tabular}{|c|c|c|c|c|c|}
\hline Gene & SNP & Genotype & $\mathrm{N}$ & BMI $\left(\mathrm{kg} / \mathrm{m}^{2}\right)$, mean & $\pm \mathrm{SD} p$-value \\
\hline \multirow{5}{*}{ NEGRI } & \multirow{5}{*}{ rs2568958 } & AA & 239 & $26.71 \pm 4.30$ & \multirow{3}{*}{0.042} \\
\hline & & AG & 233 & $26.12 \pm 4.02$ & \\
\hline & & GG & 74 & $25.57 \pm 4.47$ & \\
\hline & & AA & 239 & $26.71 \pm 4.30$ & \multirow{2}{*}{0.047} \\
\hline & & $\mathrm{AG}+\mathrm{GG}$ & 307 & $25.99 \pm 4.14$ & \\
\hline \multirow{10}{*}{ FTO } & \multirow{5}{*}{ rs6499640 } & AA & 209 & $25.80 \pm 4.04$ & \multirow{3}{*}{0.048} \\
\hline & & $\mathrm{AG}$ & 258 & $26.75 \pm 4.50$ & \\
\hline & & GG & 76 & $26.30 \pm 3.61$ & \\
\hline & & AA & 209 & $25.80 \pm 4.04$ & \multirow{2}{*}{0.022} \\
\hline & & $\mathrm{AG}+\mathrm{GG}$ & 334 & $26.65 \pm 4.31$ & \\
\hline & \multirow{5}{*}{ rs3751812 } & GG & 195 & $25.82 \pm 3.97$ & \multirow{3}{*}{0.045} \\
\hline & & GT & 255 & $26.73 \pm 4.59$ & \\
\hline & & TT & 95 & $26.21 \pm 3.56$ & \\
\hline & & GG & 195 & $25.82 \pm 3.97$ & \multirow{2}{*}{0.041} \\
\hline & & $\mathrm{GT}+\mathrm{TT}$ & 359 & $26.59 \pm 4.34$ & \\
\hline \multirow{10}{*}{$S H 2 B 1$} & \multirow{5}{*}{ rs 4788102} & GG & 250 & $25.82 \pm 4.09$ & \multirow[b]{2}{*}{0.038} \\
\hline & & GA & 225 & $26.79 \pm 4.32$ & \\
\hline & & AA & 69 & $26.57 \pm 4.25$ & \\
\hline & & GG & 250 & $25.82 \pm 4.09$ & \\
\hline & & $\mathrm{GA}+\mathrm{AA}$ & 294 & $26.74 \pm 4.30$ & 0.012 \\
\hline & \multirow{5}{*}{ rs8049439 } & TT & 240 & $25.80 \pm 3.94$ & \multirow{3}{*}{0.049} \\
\hline & & $\mathrm{TC}$ & 218 & $26.70 \pm 4.29$ & \\
\hline & & $\mathrm{CC}$ & 74 & $26.61 \pm 4.17$ & \\
\hline & & TT & 240 & $25.80 \pm 3.94$ & 0.015 \\
\hline & & $\mathrm{TC}+\mathrm{CC}$ & 292 & $26.68 \pm 4.26$ & 0.015 \\
\hline \multirow{5}{*}{\multicolumn{2}{|c|}{$H T R 2 C$ rs3813929 }} & $\mathrm{CC}$ & 400 & $26.65 \pm 4.26$ & \multirow{3}{*}{0.003} \\
\hline & & $\mathrm{CT}$ & 92 & $25.05 \pm 4.54$ & \\
\hline & & TT & 57 & $25.94 \pm 2.79$ & \\
\hline & & $\mathrm{CC}$ & 400 & $26.65 \pm 4.26$ & \multirow{2}{*}{0.002} \\
\hline & & $\mathrm{CT}+\mathrm{TT}$ & 149 & $25.39 \pm 3.98$ & \\
\hline
\end{tabular}

BMI, Body mass index.

"fat metabolism" and/or "bone". Single nucleotide polymorphisms (SNPs) were selected in accordance with the following criteria: known functional or potentially functional consequence, place in promoter regions, minor allele frequency (MAF) $>0.5$ in Caucasian subjects (polymorphisms with allele frequencies $<5 \%$ were excluded), distribution and localization in the gene (upstream and downstream regions included) and low linkage disequilibrium (LD) between genetic variants (recombination frequency $<30 \%$ ). We used HapMap and NCBI databases to collect information about polymorphisms and to establish the gene and pathway involved in each SNPs. SNPlex oligonucleotide ligation assay (Applied Biosystems, Foster City, CA, USA) was used to genotyping according to the manufacturer's guidelines.

\subsection{Statistical analysis}

Qualitative variables were expressed as absolute (n) and relative (\%) frequencies and quantitative variables as mean (standard deviation(SD)). To analyze differences between quantitative variables was used the $T$-test, applying the Bonferroni adjustment. The chi-square test was used to study qualitative variables. Hardy-Weinberg equilibrium, using the chi-square test, was used to test the control group for each SNPs. To evaluate the relationship between the SNPs with overweight, obesity and osteoporotic bone fracture; odd ratios (ORs) with $95 \%$ confidence intervals (CI) were calculated for each variant applying unconditional logistic regression models. $p$-values were adjusted by age, sex, hypertension, menopause, BMD, and family history of osteoporotic bone fracture. The first step was a screening phase in which the influence of the SNPs in obesityrelated genes on BMI levels, overweight and obesity status were analysed. Analysis of the relationship between SNPs in obesity-related genes and the susceptibility to suffer osteoporotic bone fracture only included the genetic variants which yielded significant associations with BMI, overweight or obesity.

A statistical power analysis to study the relationship between fracture and SNPs was carried out. With effect size moderate: 0.5 ; degree freedom: 2; sample size: 500 and level of significance: 0.05 ; the results showed a power $=1$. The results showed a power $=0.99947$ with effect size small: 0.23 ; degree freedom: 2; sample size: 500 and, level of significance: 0.05 . An $\mathrm{OR}=1.88$ (power: 0.80 ), $\mathrm{OR}=2.43$ (power: 0.97 ) and $\mathrm{OR}=3.1$ (power: 0.99 ) was showed by the analysis to detect the power of the statistical significance of the OR with a genotypic basal probability: 0.20 , event probability: 0.40 , level of significance: 0.05 , and sample size: 500 . The statistical analyses were made using SPSS software (version 21.0, IBM Corp., Chicago, IL, USA). A $p$-value $<0.05$ was regarded as significant.

\section{Results}

The study sample included 575 subjects after a 1214 year follow up with a mean age of $61.62 \pm 17.1$ years and $50.9 \%(\mathrm{n}=296)$ were female. The mean BMI was 26.30 (4.2). There were 202 subjects who were overweight (37.15\%) and 143 who were obese (26.55\%). 221 subjects with osteoporotic bone fracture and 354 individuals without bone fracture were included. Table 1 summarizes the anthropometric, demographic and clinical features between individuals with osteoporotic fracture and controls. There were no significant differences except that the family history of osteoporotic bone fracture was more frequent in subjects with bone fractures $(p=0.021)$ (Table 1$)$. The sample size was sufficient for the study objectives according to the statistical power analysis.

The significant results of the relationship between SNPs in obesity-related genes and BMI levels, and overweight and obesity are summarized in Tables 2,3,4. The distribution of the SNPs included were in Hardy-Weinberg equilibrium. Table 2 shows the significant BMI variations according to polymorphisms in obesity-related genes. The 
Table 3. Genotypic frequencies of genetic variants in obesity-related genes significantly associated with overweight.

\begin{tabular}{|c|c|c|c|c|c|c|}
\hline Gene & SNP & Genotype & Subjects without overweight (n (\%)) & Subjects with overweight (n (\%)) & $p$-value & OR $(95 \% \mathrm{CI})$ \\
\hline \multirow{7}{*}{ ETV5 } & \multirow{7}{*}{ rs7647305 } & $\mathrm{CC}$ & $200(61.2 \%)$ & $120(62 \%)$ & - & 1.00 \\
\hline & & CT & $117(35.8 \%)$ & $57(29.7 \%)$ & 0.294 & $0.81(0.55-1.19)$ \\
\hline & & TT & $10(3.1 \%)$ & $15(7.8 \%)$ & 0.031 & $2.50(1.18-5.74)$ \\
\hline & & $\mathrm{CC}+\mathrm{CT}$ & $317(96.9 \%)$ & $177(92.2 \%)$ & - & 1.00 \\
\hline & & $\mathrm{TT}$ & $10(3.1 \%)$ & $15(7.8 \%)$ & 0.018 & $2.68(1.18-6.11)$ \\
\hline & & $\mathrm{CC}$ & $200(61.2 \%)$ & $120(62 \%)$ & \multirow{2}{*}{0.762} & \multirow{2}{*}{ - } \\
\hline & & $\mathrm{CT}+\mathrm{TT}$ & $127(38.8 \%)$ & $72(37.5 \%)$ & & \\
\hline \multirow{7}{*}{ FTO } & \multirow{7}{*}{ rs8044769 } & $\mathrm{CC}$ & $83(25.2 \%)$ & $69(34.8 \%)$ & - & 1.00 \\
\hline & & $\mathrm{CT}$ & $171(52.0 \%)$ & $80(40.4 \%)$ & 0.007 & $0.56(0.37-0.85)$ \\
\hline & & $\mathrm{TT}$ & $75(22.8 \%)$ & $49(24.7 \%)$ & 0.326 & $0.78(0.48-1.27)$ \\
\hline & & $\mathrm{CC}+\mathrm{CT}$ & $254(77.2 \%)$ & $149(75.3 \%)$ & \multirow{2}{*}{0.609} & \multirow{2}{*}{ - } \\
\hline & & $\mathrm{TT}$ & $75(22.8 \%)$ & $49(24.7 \%)$ & & \\
\hline & & $\mathrm{CC}$ & $83(25.2 \%)$ & $69(34.8 \%)$ & - & 1.00 \\
\hline & & $\mathrm{CT}+\mathrm{TT}$ & $246(74.8 \%)$ & $129(65.2 \%)$ & 0.019 & $0.63(0.43-0.92)$ \\
\hline \multirow{7}{*}{$A D R B 2$} & \multirow{7}{*}{ rs12654778 } & GG & $149(44.5 \%)$ & $74(36.8 \%)$ & \multirow{3}{*}{0.065} & \multirow{3}{*}{ - } \\
\hline & & GA & $142(42.4 \%)$ & $87(43.3 \%)$ & & \\
\hline & & $\mathrm{AA}$ & $44(13.1 \%)$ & $40(19.9 \%)$ & & \\
\hline & & $\mathrm{GG}+\mathrm{GA}$ & $291(86.9 \%)$ & $161(80.1 \%)$ & - & 1.00 \\
\hline & & $\mathrm{AA}$ & $44(13.1 \%)$ & $40(19.9 \%)$ & 0.038 & $1.64(1.21-2.62)$ \\
\hline & & GG & $149(44.5 \%)$ & $74(36.8 \%)$ & \multirow{2}{*}{0.086} & \multirow{2}{*}{-} \\
\hline & & $\mathrm{GA}+\mathrm{AA}$ & $186(55.5 \%)$ & $127(63.2 \%)$ & & \\
\hline \multirow{7}{*}{ KCTD15 } & \multirow{7}{*}{ rs11084753 } & GG & $146(44.0 \%)$ & $91(45.5 \%)$ & \multirow{3}{*}{0.119} & \multirow{3}{*}{-} \\
\hline & & GA & $136(41.0 \%)$ & $91(45.5 \%)$ & & \\
\hline & & $\mathrm{AA}$ & $50(15.1 \%)$ & $18(9.0 \%)$ & & \\
\hline & & $\mathrm{GG}+\mathrm{GA}$ & $282(84.9 \%)$ & $182(91.0 \%)$ & - & 1.00 \\
\hline & & $\mathrm{AA}$ & $50(15.1 \%)$ & $18(9.0 \%)$ & 0.045 & $0.55(0.31-0.78)$ \\
\hline & & GG & $146(44.0 \%)$ & $91(45.5 \%)$ & \multirow{2}{*}{0.732} & \multirow{2}{*}{-} \\
\hline & & $\mathrm{GA}+\mathrm{AA}$ & $186(56.0 \%)$ & $109(54.5 \%)$ & & \\
\hline
\end{tabular}

OR, odds ratio; $\mathrm{CI}$, confidence interval.

variant genotypes of the rs2568958 NEGR1 and rs3813929 HTR2C polymorphisms were associated with a lower BMI ( $p=0.042$ and $p=0.002)$ and subjects with the variant genotypes of the rs8049439 SH2B1, rs4788102 SH2B1, rs6499640 FTO and rs3751812 FTO polymorphisms had a higher BMI $(p=0.015, p=0.012, p=0.022$ and $p$ $=0.041$, respectively) (Table 2). Carrying the $\mathrm{AG}+\mathrm{GG}$ genotype of the rs2568958 NEGR1 polymorphism and the $\mathrm{CT}+\mathrm{TT}$ genotype of the HTR2C SNP was associated with a lower BMI $(p<0.001)$. The combined effect of the genotypes was observed in 80 subjects with a BMI of $24.32 \pm$ $3.38 \mathrm{~kg} / \mathrm{m}^{2}$. Subjects carrying the variant alleles of the rs6499640 FTO, rs3751812 FTO, rs4788102 SH2B1 and rs8049439 SH2B1 polymorphisms were associated with a higher BMI $(p=0.002)$. This effect was observed in 109 subjects with a BMI of $27.75 \pm 4.43 \mathrm{~kg} / \mathrm{m}^{2}$. The genotypic frequencies of the polymorphisms were also analysed between overweight and non-overweight subjects (Table 3) and between obese and non-obese subjects (Table 4). Polymorphisms in the ETV5, ADRB2, FTO and TMEM18 genes were associated with overweight or obesity. The variant genotype of the rs7647305 ETV5 and rs 12654778 ADRB2 SNPs were associated with an increased risk of overweight $(p=0.018$ and $p=0.038)$. The variant genotype of the rs8044769 FTO and rs11084753 KCTD15 SNPs were associated with a decreased risk of overweight ( $p=0.019$ and $p=0.045$ ) (Table 3). The rs8044769 FTO SNPs was also relationated with a decreased risk of obesity $(p=0.039)$ (Table 4). The rs2867125, rs6548238 and rs 4854344 polymorphisms in the TMEM18 gene were associated with obesity $(p=0.045, p=0.034$ and $p=0.041)$ (Table 4).

Analysis of the relationship between polymorphisms in obesity-related genes and the risk of osteoporotic bone fracture only included polymorphisms associated with BMI, overweight and obesity. The genotype distribution of these polymorphisms in subjects without bone fracture was in Hardy-Weinberg equilibrium. Genetic variants in the NEGRI and FTO genes were associated with bone fracture. The GG genotype and $\mathrm{G}$ allele of the rs 2568958 NEGR1 polymorphism were associated with a decreased risk of osteoporotic fracture $(p=0.009$ and $p=0.010)$ (Table 5). In addition, polymorphisms in the FTO gene were relationated with the susceptibility to osteoporotic fracture. The TT genotype of the rs 8044769 , the GG genotype of rs6499649 and the TT genotype of rs3751812 FTO gene variants were relationated with a decreased risk of osteo- 
Table 4. Genotypic frequencies of genetic variants in obesity-related genes significantly associated with obesity.

\begin{tabular}{|c|c|c|c|c|c|c|}
\hline Gene & SNP & Genotype & Subjects without obesity (n (\%)) & Subjects with obesity (n (\%)) & $p$-value & OR $(95 \% \mathrm{CI})$ \\
\hline \multirow{21}{*}{ TMEM18 } & \multirow{7}{*}{ rs 2867125} & GG & $270(69.1 \%)$ & $110(78.0 \%)$ & \multirow{3}{*}{0.072} & \multirow{3}{*}{-} \\
\hline & & GA & $109(27.9 \%)$ & $30(21.6 \%)$ & & \\
\hline & & AA & $12(3.1 \%)$ & $1(0.7 \%)$ & & \\
\hline & & $\mathrm{GG}+\mathrm{GA}$ & $379(96.9 \%)$ & $140(99.3)$ & \multirow{2}{*}{0.120} & \multirow{2}{*}{-} \\
\hline & & AA & $12(3.1 \%)$ & $1(0.7 \%)$ & & \\
\hline & & GG & $270(69.1 \%)$ & $110(78.0 \%)$ & - & 1.00 \\
\hline & & $\mathrm{GA}+\mathrm{TT}$ & $121(30.9 \%)$ & $31(220 \%)$ & 0.045 & $0.62(0.40-0.83)$ \\
\hline & \multirow{7}{*}{ rs6548238 } & $\mathrm{CC}$ & $269(67.9 \%)$ & $110(77.5 \%)$ & \multirow{3}{*}{0.052} & \multirow{3}{*}{-} \\
\hline & & $\mathrm{CT}$ & $114(28.8 \%)$ & $31(21.8 \%)$ & & \\
\hline & & TT & $13(3.3 \%)$ & $1(0.7 \%)$ & & \\
\hline & & $\mathrm{CC}+\mathrm{CT}$ & $383(96.7 \%)$ & $141(99.3 \%)$ & \multirow{2}{*}{0.098} & \multirow{2}{*}{-} \\
\hline & & TT & $13(3.3 \%)$ & $1(0.7 \%)$ & & \\
\hline & & $\mathrm{CC}$ & $269(67.9 \%)$ & $110(77.5 \%)$ & - & 1.00 \\
\hline & & $\mathrm{CT}+\mathrm{TT}$ & $127(32.1 \%)$ & $32(22.5 \%)$ & 0.034 & $0.61(0.39-0.86)$ \\
\hline & \multirow{7}{*}{ rs4854344 } & TT & $269(67.8 \%)$ & $110(76.9 \%)$ & \multirow{3}{*}{0.057} & \multirow{3}{*}{-} \\
\hline & & TG & $115(29.0 \%)$ & $32(22.4 \%)$ & & \\
\hline & & GG & $13(3.3 \%)$ & $1(0.7 \%)$ & & \\
\hline & & $\mathrm{TT}+\mathrm{TG}$ & $384(96.7 \%)$ & $142(99.3 \%)$ & \multirow{2}{*}{0.097} & \multirow{2}{*}{-} \\
\hline & & GG & $13(3.3 \%)$ & $1(0.7 \%)$ & & \\
\hline & & $\mathrm{TT}$ & $269(67.8 \%)$ & $110(76.9 \%)$ & - & 1.00 \\
\hline & & $\mathrm{TG}+\mathrm{GG}$ & $128(32.2 \%)$ & $33(23.1 \%)$ & 0.041 & $0.63(0.40-0.89)$ \\
\hline \multirow{7}{*}{ FTO } & \multirow{7}{*}{ rs8044769 } & $\mathrm{CC}$ & $111(28.5 \%)$ & $52(38.0 \%)$ & - & 1.00 \\
\hline & & $\mathrm{CT}$ & $196(50.3 \%)$ & $51(37.2 \%)$ & 0.011 & $0.55(0.34-0.87)$ \\
\hline & & $\mathrm{TT}$ & $83(21.3 \%)$ & $34(24.8 \%)$ & 0.611 & $0.87(0.52-1.46)$ \\
\hline & & $\mathrm{CC}+\mathrm{CT}$ & $307(78.7 \%)$ & $103(72.2 \%)$ & \multirow{2}{*}{0.392} & \multirow{2}{*}{-} \\
\hline & & TT & $83(21.3 \%)$ & $34(24.8 \%)$ & & \\
\hline & & $\mathrm{CC}$ & $111(28.5 \%)$ & $52(38.0 \%)$ & - & 1.00 \\
\hline & & $\mathrm{CT}+\mathrm{TT}$ & $279(71.5 \%)$ & $85(62.0 \%)$ & 0.039 & $0.65(0.43-0.89)$ \\
\hline
\end{tabular}

OR, odds ratio; $\mathrm{CI}$, confidence interval.

porotic bone fracture $(p=0.001, p=0.005$ and $p=0.002)$ (Table 5). These SNPs were also associated with BMI, overweight and obesity (Tables 2,3,4). The risk of osteoporotic fracture was also analysed in subjects with overweight or obesity (Table 6 ). The variant genotype and variant allele of the rs2568958 NEGR1 and rs8044769 FTO SNPs were associated with a decreased risk of osteoporotic bone fracture (for subjects with overweight: $p=0.032$ and $p$ $=0.013$; for subjects with obesity: $p=0.035$ and $p=0.005$ ).

\section{Discussion}

Obesity and osteoporosis are closely correlated genetically due to the common biological pathways of fat and bone metabolism, implying that genes may be crucial in both processes [23-25]. Multiple pleiotropic loci and candidate genes involved in obesity and osteoporosis have been studied [23,24,35], although more common genes underlying both pathologies have not been identified. Therefore, we studied whether SNPs in obesity-related genes modify the susceptibility to osteoporotic bone fracture. The results showed that polymorphisms in the NEGRI and FTO genes were relationated with this risk. Analysis of the relationship between SNPs in obesity-related genes and the risk of os- teoporotic fracture only included the genetic variants which yielded significant associations with BMI, overweight and obesity.

Susceptibility to obesity is determined by environmental factors, with an important genetic component. Familial and twin studies have shown that genetic factors are crucial in around $40-70 \%$ of cases [33-35]. The Srchomology (SH2)-B protein is a crucial regulator of leptin and insulin sensitivity, glucose homeostasis, and body weight [36]. It has also been reported that $S H 2 B 1$ knockout mice developed obesity and diabetes [37]. We found an association between the rs 4788102 and rs8049439 SH2B polymorphisms and BMI, in line with previous studies which correlated multiple genetic variants in the $S H 2 B$ gene with body weight regulation [38-40]. We also found a relationship between the variant allele of the rs3813929 HTR $2 C$ polymorphism and BMI. The HTR2C gene encodes to the serotonin 5-HT-2C receptor, which is involved in appetite control, feeding behaviour and the risk of obesity [41,42]. The rs 3813929 polymorphism is found in the promotor region of the HTR2C gene and has been associated with alterations in body weight, as it modified HTR2C gene expression $[43,44]$. Transcription factor E- 
Table 5. Genotypic frequencies of genetic variants in obesity-related genes significantly associated with the risk of osteoporotic bone fracture.

\begin{tabular}{|c|c|c|c|c|c|c|}
\hline Gene & SNP & Genotype & Control subjects (n (\%)) & Patients with OF (n (\%)) & $p$-value & OR $(95 \% \mathrm{CI})$ \\
\hline \multirow{7}{*}{ NEGR1 } & \multirow{7}{*}{ rs 2568958} & AA & $137(39.5 \%)$ & $111(50.5 \%)$ & - & 1.00 \\
\hline & & AG & $159(45.8 \%)$ & $90(40.9 \%)$ & 0.051 & $0.69(0.48-1.10)$ \\
\hline & & GG & $51(14.7 \%)$ & $19(8.6 \%)$ & 0.009 & $0.46(0.25-0.82)$ \\
\hline & & $\mathrm{AA}+\mathrm{AG}$ & $296(85.3 \%)$ & $201(91.4 \%)$ & - & 1.00 \\
\hline & & GG & $51(14.7 \%)$ & $19(8.6 \%)$ & 0.034 & $0.54(0.31-0.95)$ \\
\hline & & AA & $137(39.5 \%)$ & $111(50.5 \%)$ & - & 1.00 \\
\hline & & $\mathrm{AG}+\mathrm{GG}$ & $210(60.5 \%)$ & $109(49.5 \%)$ & 0.010 & $0.64(0.45-0.91)$ \\
\hline \multirow{21}{*}{ FTO } & \multirow{7}{*}{ rs8044769 } & $\mathrm{CC}$ & $139(41.1 \%)$ & $112(51.4 \%)$ & - & 1.00 \\
\hline & & $\mathrm{CT}$ & $103(30.5 \%)$ & $69(31.7 \%)$ & 0.358 & $0.83(0.56-1.23)$ \\
\hline & & $\mathrm{TT}$ & $96(28.4 \%)$ & $37(17.0 \%)$ & 0.001 & $0.47(0.30-0.75)$ \\
\hline & & $\mathrm{CC}+\mathrm{CT}$ & $242(71.6 \%)$ & $181(83.0 \%)$ & - & 1.00 \\
\hline & & TT & $96(28.4 \%)$ & $37(17.0 \%)$ & 0.002 & $0.51(0.33-0.78)$ \\
\hline & & $\mathrm{CC}$ & $139(41.1 \%)$ & $112(51.4 \%)$ & - & 1.00 \\
\hline & & $\mathrm{CT}+\mathrm{TT}$ & $199(58.9 \%)$ & $106(48.6 \%)$ & 0.018 & $0.66(0.46-0.93)$ \\
\hline & \multirow{7}{*}{ rs6499649 } & AA & $119(34.6 \%)$ & $89(40.6 \%)$ & - & 1.00 \\
\hline & & AG & $158(45.9 \%)$ & $107(48.9 \%)$ & 0.597 & $0.90(0.62-1.30)$ \\
\hline & & GG & $67(19.5 \%)$ & $23(10.5 \%)$ & 0.005 & $0.45(0.26-0.79)$ \\
\hline & & $\mathrm{AA}+\mathrm{AG}$ & $277(80.5 \%)$ & $196(89.5 \%)$ & - & 1.00 \\
\hline & & GG & $67(19.5 \%)$ & $23(10.5 \%)$ & 0.005 & $0.48(0.29-0.80)$ \\
\hline & & AA & $119(34.6 \%)$ & $89(40.6 \%)$ & \multirow{2}{*}{0.147} & \multirow{2}{*}{-} \\
\hline & & $\mathrm{AG}+\mathrm{GG}$ & $225(65.4 \%)$ & $130(59.4 \%)$ & & \\
\hline & \multirow{7}{*}{ rs 3751812} & GG & $123(35.5 \%)$ & $96(43.6 \%)$ & - & 1.00 \\
\hline & & GT & $161(46.5 \%)$ & $104(47.3 \%)$ & 0.308 & $0.82(0.57-1.19)$ \\
\hline & & $\mathrm{TT}$ & $62(17.9 \%)$ & $20(9.1 \%)$ & 0.002 & $0.41(0.23-0.73)$ \\
\hline & & $\mathrm{GG}+\mathrm{GT}$ & $284(82.1 \%)$ & $200(90.9 \%)$ & - & 1.00 \\
\hline & & $\mathrm{TT}$ & $62(17.9 \%)$ & $20(9.1 \%)$ & 0.004 & $0.45(0.25-0.78)$ \\
\hline & & GG & $123(35.5 \%)$ & $96(43.6 \%)$ & \multirow{2}{*}{0.055} & \multirow{2}{*}{-} \\
\hline & & $\mathrm{GT}+\mathrm{TT}$ & $223(64.5 \%)$ & $124(56.4 \%)$ & & \\
\hline
\end{tabular}

OF, osteoporotic fracture; OR, odds ratio; CI, confidence interval.

twenty-six version 5 (Etv5) has been linked with obesity as it is involved in adipogenesis and it has been reported that ETV5 knockout mice have reduced fat mass and are resistant to obesity $[45,46]$. The results reported a relationship between the rs7647305 ETV5 polymorphism and overweight subjects, in line with other reports [47,48]. The $A D R B 2$ gene encodes to adrenergic-receptor beta 2, which plays a key role in fat metabolism by increasing lipolysis and thermogenesis $[49,50]$. We found the variant genotype of the rs12654778 ADRB2 SNPs was associated with overweight and that the rs11084753 polymorphism in the $K C T D 15$ gene was related to overweight, similarly to the study by Willer et al. [38]. The KCTD15 gene encodes to the potassium channel tetramerization protein, which is involved in various biological processes related to obesity, such as glucose metabolism, fat metabolism and adipogenesis [51]. The results also reported an association between the rs2867125, rs6548238 and rs4854344 genetic variants in the TMEN18 gene and obesity, in line with previous studies $[33,38,40,47,48]$. Transmembrane protein 18 (Tmen18) plays a key role in the central control of appetite and body weight regulation [52] and therefore genetic variants in the TMEN18 gene could modify gene expression and the sus- ceptibility to obesity. Various studies have summarized that genetic variants in NEGRl are relationated with human body weight changes $[38,53]$, and we found an association between the variant allele of the rs2568958 NEGR1 SNPs and BMI. Neuronal growth regulator 1 (Negr1) is crucial in neural cell communication and, more recently, it has also been associated with intercellular cholesterol trafficking, suggesting a relationship with the predisposition to obesity [54]. We also found an association between the rs6499640, rs3751812 and rs8044769 genetic variants in the FTO gene with BMI and obesity. The FTO gene is one of the genes most commonly associated with susceptibility to obesity, due to its role in fat cell lipolysis. It has been reported that, in subjects with increased BMI, there is overexpression of the FTO gene in adipose tissue and that FTO-knockout mice have reduced fat mas. Overexpression of the FTO gene has been associated with increased food intake and obesity [5557]. Many polymorphisms in the FTO gene have been associated with obesity $[33,38,47,48]$. The rs3813929 HTR2C, rs8049439 ATXNL2, rs6499640 FTO and rs7647305 ETV5 polymorphisms were also associated with obesity in a previous study by our group that analysed the impact of obesityrelated genes in Spanish subjects [58]. 
Table 6. Genotypic frequencies of genetic variants in obesity-related genes significantly associated with the risk of osteoporotic bone fracture in subjects with overweight and obesity.

\begin{tabular}{|c|c|c|c|c|c|c|c|}
\hline & Gene & SNP & Genotype & Control subjects (n (\%)) & Patients with OF (n (\%)) & $p$-value & OR $(95 \% \mathrm{CI})$ \\
\hline \multirow{8}{*}{ Subjects with overweight } & \multirow{4}{*}{ NEGR1 } & \multirow{4}{*}{ rs 2568958} & AA & $51(41.5 \%)$ & $45(57.0 \%)$ & - & 1.00 \\
\hline & & & AG & $53(43.1 \%)$ & $30(38.0 \%)$ & 0.148 & $0.64(0.35-1.17)$ \\
\hline & & & $\mathrm{AA}+\mathrm{AG}$ & $104(84.6 \%)$ & $75(94.9 \%)$ & - & 1.00 \\
\hline & & & GG & $19(15.4 \%)$ & $4(5.1 \%)$ & 0.031 & $0.29(0.11-0.89)$ \\
\hline & \multirow[b]{4}{*}{ FTO } & \multirow[b]{4}{*}{ rs8044769 } & $\mathrm{CC}$ & $46(38.3 \%)$ & $44(56.4 \%)$ & - & 1.00 \\
\hline & & & $\mathrm{CT}$ & $38(31.7 \%)$ & $23(29.5 \%)$ & 0.176 & $0.63(0.32-1.22)$ \\
\hline & & & $\mathrm{TT}$ & $36(30.0 \%)$ & $11(14.1 \%)$ & 0.005 & $0.31(0.14-0.70)$ \\
\hline & & & $\mathrm{CC}+\mathrm{CT}$ & $84(70.0 \%)$ & $67(85.9 \%)$ & - & 1.00 \\
\hline \multirow{9}{*}{ Subjects with obesity } & \multirow{7}{*}{$N E G R 1$} & \multirow{7}{*}{ rs 2568958} & AA & $32(39.5 \%)$ & $34(57.6 \%)$ & \multirow{3}{*}{0.073} & \multirow{3}{*}{-} \\
\hline & & & $\mathrm{AG}$ & $39(48.1 \%)$ & $22(37.3 \%)$ & & \\
\hline & & & GG & $10(12.3 \%)$ & $3(5.1 \%)$ & & \\
\hline & & & $\mathrm{AA}+\mathrm{AG}$ & $71(87.7 \%)$ & $56(94.9 \%)$ & \multirow{2}{*}{0.156} & \multirow{2}{*}{-} \\
\hline & & & GG & $10(12.3 \%)$ & $3(5.1 \%)$ & & \\
\hline & & & AA & $32(39.5 \%)$ & $34(57.6 \%)$ & - & 1.00 \\
\hline & & & $\mathrm{AG}+\mathrm{GG}$ & $49(60.5 \%)$ & $25(42.4 \%)$ & 0.035 & $0.48(0.24-0.95)$ \\
\hline & \multirow{2}{*}{ FTO } & \multirow{2}{*}{ rs8044769 } & $\mathrm{CC}$ & $32(41.0 \%)$ & $38(65.5 \%)$ & - & 1.00 \\
\hline & & & $\mathrm{CT}$ & $24(30.8 \%)$ & $15(25.9 \%)$ & 0.115 & $0.52(0.23-1.16)$ \\
\hline
\end{tabular}

OF, osteoporotic fracture; OR, odds ratio; CI, confidence interval.

Genetic factors are important in the individual susceptibility of osteoporotic bone fracture [59]. Our results confirmed the association between family history of osteoporotic fracture and the risk of bone fracture. To analyse the influence of polymorphisms in obesity-related genes on the susceptibility to osteoporotic bone fracture, we studied 13 SNPs in eight obesity-related genes associated with body weight variations. The results showed that SNPs in the NEGRl and FTO genes were associated with the risk of osteoporotic bone fracture. Bone fragility and the increased risk of fracture observed in osteoporosis is the consequence of the imbalance between bone resorption mediated by osteoclasts and osteoblast-mediated bone formation [6]. NEGR1 could be important in bone metabolism alterations, as its role in regulating osteoblast differentiation and the cell adhesion pathway has been reported [60]. We showed that the rs2568958 genetic variant in the NEGR1 obese-related gene was associated with the susceptibility to osteoporotic bone fracture. In our knowledge, this is the first report that summarizes the association between SNPs in the NEGR1 gene and the risk of osteoporotic fracture. Polymorphisms in the NEGR1 gene could modify its expression and, therefore, osteoblast differentiation, increas- ing the risk of osteoporosis and bone fracture. We also described an association between the rs8044769, rs6499649 and rs3751812 SNPs in the FTO gene and the risk of fracture. The loss of BMSC function may lead to enhanced pathological changes in the bone metabolism, including osteoporosis and bone fracture, as the differentiation of BMSC is crucial in osteogenesis [61-63]. The FTO gene is expressed in osteoblasts and is required for maintenance of bone mass due to its key role in osteoblast differentiation from BMSC $[64,65]$. It is reported that FTO-knockout mice showed growth retardation and low BMD [66]. Other genetic variants in the FTO gene have been associated with BMD variations and susceptibility to hip fracture $[67,68]$. However, to our knowledge, this is the first time that the rs8044769, rs6499649 and rs3751812 FTO polymorphisms have been associated with osteoporotic bone fracture, supporting the hypothesis that the FTO gene might be a candidate for osteoporosis and bone fracture. Analysis of the risk of bone fracture only in subjects with overweight or obesity showed that the rs 2568958 NEGR 1 and rs8044669 FTO SNPs were relationated with bone fracture, confirming the importance of these genetic variants in the susceptibility to bone fracture. 
The principal limitation of the study is that it would have been attractive to determine the relationship of these SNPs in obese-related genes with central BMD; however, we only measured calcaneal BMD. The number of the individuals included was limited although the statistical power analysis revealed that the sample size was appropriate for our objectives. Another limitation was the bias in selecting obesity-related SNPs using available databases instead of genome-wide analysis of obesity-associated genes by running a GWAS on the Hortega follow-up cohort. The principal strength of the study is that the analysis is based on a cohort of individuals from a study with a follow-up of $12-$ 14 years. Another strength is the similarity of subjects with fracture and control group, which is crucial for the determination of the influence of genetic factors.

\section{Conclusions}

In conclusion, we describe associations between variants in the FTO and NEGR 1 genes and the susceptibility to osteoporotic bone fracture, reinforcing the hypothesis that obesity and bone metabolism are closely correlated genetically. However, studies are needed to clarify the role of these genetic variants in the susceptibility to osteoporotic bone fracture. Developing in-vitro and in-vivo functional studies to determine the role of the FTO and NEGR1 genes and their genetic variants on the susceptibility of suffering bone fracture could be very interesting; for example, studying the importance of these genetic variants in bone remodelling.

\section{Abbreviations}

BMD, Bone mineral density; BMSC, bone marrow stem cells; BMI, body mass index; WHO, World Health Organization; PIXI, peripheral instantaneous X-ray imaging; 95\% CI, 95\% confidence intervals; ORs, Odd ratios; SH2, Src-homology-B; Etv5, E-twenty-six version 5; Negr1, neuronal growth regulator 1 .

\section{Author contributions}

RUM and JLPC performed the statistical analysis, analysed and interpreted results and wrote the manuscript. JMV performed the statistical analysis. FLH, ABGG and FJC obtained genetic data, contributed to analysis and interpretation and reviewed the manuscript. LBF, JAO, JCME obtained population data, made critical revisions of the manuscript and contributed to the discussion. RUM, JLPC, FJC and JCME designed the study.

\section{Ethics approval and consent to participate}

The experimental protocol was in accordance with the Declaration of Helsinki (2008) of the World Medical Association and was approved by the University Hospital of Valladolid Ethics Committee. It was also in compliance with Spanish data protection laws (LO 15/1999) and specifica- tions (RD 1720/2007). All subjects who agreed to participate gave written informed consent.

\section{Acknowledgment}

We thank patients for their participation and the members of the Hortega Study who collected clinical data.

\section{Funding}

This study was supported by grants from Carlos III Health Institute (Ministry of Economy and Competitiveness, Spanish Government) (ISC IIII-FEDER: PI14/00874 and PI17/00544).

\section{Conflict of interest}

The authors declare no conflict of interest. RUM and JLPC are serving as guest editors in this journal. We declare that RUM and JLPC had no involvement in the peer review of this article and has no access to information regarding its peer review. Full responsibility for the editorial process for this article was delegated to AG.

\section{Supplementary material}

Supplementary material associated with this article can be found, in the online version, at https://www.imrpre ss.com/journal/FBL/27/1/10.31083/j.fbl2701032.

\section{References}

[1] Kanis JA. Diagnosis of osteoporosis. Osteoporosis International. 1997; 7: 108-116.

[2] Yang T, Shen H, Liu A, Dong S, Zhang L, Deng F, et al. A road map for understanding molecular and genetic determinants of osteoporosis. Nature Reviews Endocrinology. 2020; 16: 91103.

[3] Adachi JD, Adami S, Gehlbach S, Anderson FA, Boonen S, Chapurlat RD, et al. Impact of Prevalent Fractures on Quality of Life: Baseline Results from the Global Longitudinal Study of Osteoporosis in Women. Mayo Clinic Proceedings. 2010; 85: 806-813.

[4] Kanis JA. Diagnosis of osteoporosis and assessment of fracture risk. The Lancet. 2002; 359: 1929-1936.

[5] Sheer RL, Barron RL, Sudharshan L, Pasquale MK. Validated prediction of imminent risk of fracture for older adults. The American Journal of Managed Care. 2020; 26: e91-e97.

[6] Zaidi M. Skeletal remodeling in health and disease. Nature Medicine. 2007; 13: 791-801.

[7] Liu Y, Zhang L, Papasian CJ, Deng H. Genome-wide Association Studies for Osteoporosis: a 2013 Update. Journal of Bone Metabolism. 2014; 21: 99-116.

[8] Zhang L, Choi HJ, Estrada K, Leo PJ, Li J, Pei YF, et al. Multistage genome-wide association meta-analyses identified two new loci for bone mineral density. Human molecular genetics. 2014; 23: 1923-33.

[9] Trajanoska K, Rivadeneira F. The genetic architecture of osteoporosis and fracture risk. Bone. 2019; 126: 2-10.

[10] Stewart TL, Ralston SH. Role of genetic factors in the pathogenesis of osteoporosis. The Journal of Endocrinology. 2000; 166: 235-245.

[11] Rivadeneira F, Mäkitie O. Osteoporosis and Bone Mass Disorders: from Gene Pathways to Treatments. Trends in Endocrinology and Metabolism. 2016; 27: 262-281. 
[12] Zhao L, Liu Y, Liu P, Hamilton J, Recker RR, Deng H. Relationship of obesity with osteoporosis. The Journal of Clinical Endocrinology and Metabolism. 2007; 92: 1640-1646.

[13] Rosen CJ, Bouxsein ML. Mechanisms of disease: is osteoporosis the obesity of bone? Nature Clinical Practice. Rheumatology. 2006; 2: 35-43.

[14] Reid IR. Relationships among body mass, its components, and bone. Bone. 2003; 31: 547-555.

[15] Gimble JM, Robinson CE, Wu X, Kelly KA. The function of adipocytes in the bone marrow stroma: an update. Bone. 1996; 19: 421-428.

[16] Georgiou KR, Scherer MA, Fan C, Cool JC, King TJ, Foster $\mathrm{BK}$, et al. Methotrexate chemotherapy reduces osteogenesis but increases adipogenic potential in the bone marrow. Journal of Cellular Physiology. 2012; 227: 909-918.

[17] Jing H, Liao L, An Y, Su X, Liu S, Shuai Y, et al. Suppression of EZH2 Prevents the Shift of Osteoporotic MSC Fate to Adipocyte and Enhances Bone Formation during Osteoporosis. Molecular Therapy. 2016; 24: 217-229.

[18] Gomez-Marcos MA, Gonzalez-Sarmiento R, Recio-Rodríguez JI, Agudo-Conde C, Gamella-Pozuelo L, Perretta-Tejedor N, et al. Relationship between target organ damage and blood pressure, retinal vessel calibre, oxidative stress and polymorphisms in VAV-2 and VAV-3 genes in patients with hypertension: a case-control study protocol (LOD-Hipertension). British Medical Journal. 2014; 4: e005112.

[19] Elefteriou F, Ahn JD, Takeda S, Starbuck M, Yang X, Liu X, et al. Leptin regulation of bone resorption by the sympathetic nervous system and CART. Nature. 2005; 434: 514-520.

[20] Ducy P, Amling M, Takeda S, Priemel M, Schilling AF, Beil FT, et al. Leptin Inhibits Bone Formation through a Hypothalamic Relay. Cell. 2000; 100: 197-207.

[21] Wang MC, Bachrach LK, Van Loan M, Hudes M, Flegal KM, Crawford PB. The relative contributions of lean tissue mass and fat mass to bone density in young women. Bone. 2005 ; 37 : 474481.

[22] von Mach M, Stoeckli R, Bilz S, Kraenzlin M, Langer I, Keller $\mathrm{U}$. Changes in bone mineral content after surgical treatment of morbid obesity. Metabolism: Clinical and Experimental. 2004; 53: 918-921.

[23] Liu L, Yang X, Zhang H, Zhang Z, Wei X, Feng G, et al. Two novel pleiotropic loci associated with osteoporosis and abdominal obesity. Human Genetics. 2020; 139: 1023-1035.

[24] Liu YZ, Pei YF, Liu JF, Yang F, Guo Y, Zhang L, et al. Powerful bivariate genome-wide association analyses suggest the SOX6 gene influencing both obesity and osteoporosis phenotypes in males. The Public Library of Science One. 2009; 4: e6827.

[25] Deng F, Lei S, Li M, Jiang C, Dvornyk V, Deng H. Genetic determination and correlation of body mass index and bone mineral density at the spine and hip in Chinese Han ethnicity. Osteoporosis International. 2006; 17: 119-124.

[26] Tellez-Plaza M, Briongos-Figuero L, Pichler G, DominguezLucas A, Simal-Blanco F, Mena-Martin FJ, et al. Cohort profile: the Hortega Study for the evaluation of non-traditional risk factors of cardiometabolic and other chronic diseases in a general population from Spain. British medical journal Open. 2019; 9: $\mathrm{e} 024073$

[27] Mansego ML, Redon J, Marin R, González-Albert V, MartinEscudero JC, Fabia MJ, et al. Renin polymorphisms and haplotypes are associated with blood pressure levels and hypertension risk in postmenopausal women. Journal of Hypertension. 2008; 26: $230-237$.

[28] Morales-Suárez-Varela MM, Mansego ML, Vicedo-Cabrera AM, Pineda-Alonso M, Llopis-González A, Martin-Moreno $\mathrm{JM}$, et al. Inefficient arterial hypertension control in patients with metabolic syndrome and its link to renin-angiotensin- aldosterone system polymorphisms. Hypertension Research. 2011; 34: 758-766.

[29] de Marco G, Garcia-Garcia AB, Real JT, Gonzalez-Albert V, Briongos-Figuero L, Cobos-Siles M, et al. Respiratory chain polymorphisms and obesity in the Spanish population, a crosssectional study. British medical journal Open. 2019; 9: e027004.

[30] Usategui-Martín R, Lendinez-Tortajada V, Pérez-Castrillón JL, Briongos-Figuero L, Abadía-Otero J, Martín-Vallejo J, et al. Polymorphisms in genes involved in inflammation, the NF-kB pathway and the renin-angiotensin-aldosterone system are associated with the risk of osteoporotic fracture. the Hortega Followup Study. Bone. 2020; 138: 115477.

[31] Genant HK, Wu CY, van Kuijk C, Nevitt MC. Vertebral fracture assessment using a semiquantitative technique. Journal of Bone and Mineral Research. 1993; 8: 1137-1148.

[32] Hu Y, Tan L, Chen X, Liu Z, Min S, Zeng Q, et al. Identification of Novel Potentially Pleiotropic Variants Associated with Osteoporosis and Obesity Using the cFDR Method. The Journal of Clinical Endocrinology \& Metabolism. 2018; 103: 125-138.

[33] Fall T, Ingelsson E. Genome-wide association studies of obesity and metabolic syndrome. Molecular and Cellular Endocrinology. 2014; 382: 740-757.

[34] Chung WK, Leibel RL. Considerations regarding the genetics of obesity. Obesity. 2008; 16 Suppl 3: S33-S39.

[35] Sheikh AB, Nasrullah A, Haq S, Akhtar A, Ghazanfar H, Nasir $\mathrm{A}$, et al. The Interplay of Genetics and Environmental Factors in the Development of Obesity. Cureus. 2017; 9: e1435.

[36] Ren D, Li M, Duan C, Rui L. Identification of SH2-B as a key regulator of leptin sensitivity, energy balance, and body weight in mice. Cell Metabolism. 2005; 2: 95-104.

[37] Herrera BM, Keildson S, Lindgren CM. Genetics and epigenetics of obesity. Maturitas. 2011; 69: 41-49.

[38] Speliotes EK, Loos RJF, Li S, Lindgren CM, Heid IM, Berndt SI, et al. Six new loci associated with body mass index highlight a neuronal influence on body weight regulation. Nature Genetics. 2009; 41: 25-34.

[39] Jamshidi Y, Snieder H, Ge D, Spector TD, O'Dell SD. The SH2B gene is associated with serum leptin and body fat in normal female twins. Obesity. 2007; 15: 5-9.

[40] Speliotes EK, Willer CJ, Berndt SI, Monda KL, Thorleifsson G, Jackson AU, et al. Association analyses of 249,796 individuals reveal 18 new loci associated with body mass index. Nature Genetics. 2010; 42: 937-948.

[41] Tecott LH, Sun LM, Akana SF, Strack AM, Lowenstein DH, Dallman MF, et al. Eating disorder and epilepsy in mice lacking 5-HT2c serotonin receptors. Nature. 1995; 374: 542-546.

[42] Vickers SP, Easton N, Webster LJ, Wyatt A, Bickerdike MJ, Dourish CT, et al. Oral administration of the 5-HT2Creceptor agonist, $\mathrm{mCPP}$, reduces body weight gain in rats over 28 days as a result of maintained hypophagia. Psychopharmacology. 2003; 167: 274-280.

[43] Pooley EC, Fairburn CG, Cooper Z, Sodhi MS, Cowen PJ, Harrison PJ. A 5-HT2C receptor promoter polymorphism (HTR2C $-759 \mathrm{C} / \mathrm{T}$ ) is associated with obesity in women, and with resistance to weight loss in heterozygotes. American Journal of Medical Genetics. Part B, Neuropsychiatric Genetics. 2004; 126B: $124-127$.

[44] Vimaleswaran KS, Zhao JH, Wainwright NW, Surtees PG, Wareham NJ, Loos RJF. Association between serotonin 5-HT$2 \mathrm{C}$ receptor gene (HTR2C) polymorphisms and obesity- and mental health-related phenotypes in a large population-based cohort. International Journal of Obesity. 2010; 34: 1028-1033.

[45] Schlesser HN, Simon L, Hofmann M, Murphy KM, Murphy T, Hess RA, et al. Effects of ETV5 (ets variant gene 5) on testis and body growth, time course of spermatogonial stem cell loss, and fertility in mice. Biology of Reproduction. 2008; 78: 483-489. 
[46] MAO Z. The Transcription Factor ETV5 Regulates Adipogenesis through PPARg Signaling Pathway. Diabetes. 2018; 67: 1984-198P.

[47] Thorleifsson G, Walters GB, Gudbjartsson DF, Steinthorsdottir $\mathrm{V}$, Sulem P, Helgadottir A, et al. Genome-wide association yields new sequence variants at seven loci that associate with measures of obesity. Nature Genetics. 2009; 41: 18-24.

[48] Zhao J, Bradfield JP, Li M, Wang K, Zhang H, Kim CE, et al. The Role of Obesity-associated Loci Identified in Genome-wide Association Studies in the Determination of Pediatric BMI. Obesity. 2009; 17: 2254-2257.

[49] Jocken JWE, Blaak EE, Schiffelers S, Arner P, van Baak MA, Saris WHM. Association of a beta-2 adrenoceptor (ADRB2) gene variant with a blunted in vivo lipolysis and fat oxidation. International Journal of Obesity. 2007; 31: 813-819.

[50] Takenaka A, Nakamura S, Mitsunaga F, Inoue-Murayama M, Udono T, Suryobroto B. Human-specific SNP in obesity genes, adrenergic receptor beta2 (ADRB2), Beta3 (ADRB3), and PPAR $\gamma 2$ (PPARG), during primate evolution. The Public Library of Science one. 2012; 7: e43461.

[51] Sonne SB, Yadav R, Yin G, Dalgaard MD, Myrmel LS, Gupta $\mathrm{R}$, et al. Obesity is associated with depot-specific alterations in adipocyte DNA methylation and gene expression. Adipocyte. 2017; 6: 124-133.

[52] Larder R, Sim MFM, Gulati P, Antrobus R, Tung YCL, Rimmington $\mathrm{D}$, et al. Obesity-associated gene TMEM18 has a role in the central control of appetite and body weight regulation. Proceedings of the National Academy of Sciences. 2017; 114: 9421-9426.

[53] Xi B, Takeuchi F, Meirhaeghe A, Kato N, Chambers JC, Morris AP, et al. Associations of genetic variants in/near body mass index-associated genes with type 2 diabetes: a systematic metaanalysis. Clinical Endocrinology. 2014; 81: 702-710.

[54] Joo Y, Kim H, Lee S, Lee S. Neuronal growth regulator 1deficient mice show increased adiposity and decreased muscle mass. International Journal of Obesity. 2019; 43: 1769-1782.

[55] Fawcett KA, Barroso I. The genetics of obesity: FTO leads the way. Trends in Genetics. 2010; 26: 266-274.

[56] Stratigopoulos G, Padilla SL, LeDuc CA, Watson E, Hattersley AT, McCarthy MI, et al. Regulation of Fto/Ftm gene expression in mice and humans. American Journal of Physiology. Regulatory, Integrative and Comparative Physiology. 2008; 294: R1185-R1196.

[57] Church C, Moir L, McMurray F, Girard C, Banks GT, Teboul L, et al. Overexpression of Fto leads to increased food intake and results in obesity. Nature Genetics. 2010; 42: 1086-1092.
[58] Martínez-García F, Mansego ML, Rojo-Martínez G, De MarcoSolar G, Morcillo S, Soriguer F, et al. Impact of obesity-related genes in Spanish population. BioMed Central Genetics. 2013; 14: 111.

[59] Mitek T, Nagraba Ł, Deszczyński J, Stolarczyk M, Kuchar E, Stolarczyk A. Genetic Predisposition for Osteoporosis and Fractures in Postmenopausal Women. Advances in Experimental Medicine and Biology. 2019; 1211: 17-24.

[60] Xu X, Jiang H, Li X, Wu P, Liu J, Wang T, et al. Bioinformatics analysis on the differentiation of bone mesenchymal stem cells into osteoblasts and adipocytes. Molecular Medicine Reports. 2017; 15: 1571-1576.

[61] Chen S, Jia L, Zhang S, Zheng Y, Zhou Y. DEPTOR regulates osteogenic differentiation via inhibiting MEG3-mediated activation of BMP4 signaling and is involved in osteoporosis. Stem Cell Research \& Therapy. 2018; 9: 185.

[62] Chiu L, Lai WT, Chang S, Wong C, Fan C, Fang C, et al. The effect of type II collagen on MSC osteogenic differentiation and bone defect repair. Biomaterials. 2014; 35: 2680-2691.

[63] Mastrogiacomo M, Papadimitropoulos A, Cedola A, Peyrin F, Giannoni P, Pearce SG, et al. Engineering of bone using bone marrow stromal cells and a silicon-stabilized tricalcium phosphate bioceramic: evidence for a coupling between bone formation and scaffold resorption. Biomaterials. 2007; 28: 13761384.

[64] Li Y, Yang F, Gao M, Gong R, Jin M, Liu T, et al. MiR-149-3p Regulates the Switch between Adipogenic and Osteogenic Differentiation of BMSCs by Targeting FTO. Molecular Therapy Nucleic Acids. 2019; 17: 590-600.

[65] Zhang Q, Riddle RC, Yang Q, Rosen CR, Guttridge DC, Dirckx $\mathrm{N}$, et al. The RNA demethylase FTO is required for maintenance of bone mass and functions to protect osteoblasts from genotoxic damage. Proceedings of the National Academy of Sciences. 2019; 116: 17980-17989.

[66] Gao X, Shin Y, Li M, Wang F, Tong Q, Zhang P. The fat mass and obesity associated gene FTO functions in the brain to regulate postnatal growth in mice. The Public Library of Science one. 2010; 5: e14005.

[67] Guo Y, Liu H, Yang T, Li SM, Li SK, Tian Q, et al. The fat mass and obesity associated gene, FTO, is also associated with osteoporosis phenotypes. The Public Library of Science one. 2011; 6: e27312.

[68] Tran B, Nguyen ND, Center JR, Eisman JA, Nguyen TV. Association between fat-mass-and-obesity-associated (FTO) gene and hip fracture susceptibility. Clinical Endocrinology. 2014; 81: $210-217$ 